Kong. Res. J. 1(2): 89-93, 2014

Kongunadu Arts and Science College, Coimbatore

\title{
WITHANIA SOMNIFERA: DETERMINATION OF ANTIOXIDANT SCAVENGING POTENTIAL ACTIVITY
}

\author{
Rajamani Gokila and Naganathan Srinath* \\ Department of Biotechnology, Kongunadu Arts and Science College, Coimbatore. \\ *Email: sri7486@gmail.com
}

\begin{abstract}
Due to an increase in modernization, people suffer from various stresses related and sexual problems. In India, with various herbal reservoirs, Withania somnifera (Ashwagandha) plays an important role in treating the vital and vigour problem as well as in treating sexual problems. We made an attempt to elevate the importance of this herbal source by understanding its antioxidant scavenging activity. We have utilized the powder of this plant fruit and processed using different solvents in 1:10 dilution by dissolving with $3 \mathrm{~g}$ of powder with $30 \mathrm{ml}$ of each solvent such as petroleum ether, chloroform ethanol, hexane, methanol and distilled water. It was found that methanol and chloroform extracts of W. somnifera, has higher antioxidant activity when compared with the standard Vitamin $\mathrm{C}$ was observed using the graph plotted as the percentage of inhibition of scavenging activity vs concentration and $\mathrm{IC}_{50}$ value was observed to be nearly 50 $\mu \mathrm{g} / \mathrm{mL}$ for all the tests.
\end{abstract}

Key words: W. somnifera, DPPH•, ABTS ${ }^{+}$, FRAP

\section{INTRODUCTION}

Vitality and Vigour are the most preferred things in any individual and these things are essential in this modern world to harness various new work. Indian medicine has always believed to provide a source of vitality and vigour with the help of herbal medicinal approach using Ayurveda, Siddha, Unani and Homeopathy as a common way for treating using various herbal preparations of whole plant and their products to treat the common problems time immemorial (Samhita, 1997).

The World Health Organization (WHO) has found that out off 3000 plants most of them are available in India and the usages of these plants are nearly by $80 \%$ of the world population (WHO report, 2009). With an increase rate of over exposure towards various antibiotics has created an environment of multidrug resistance microbes such as Escherichia coli, Klebsiella pneumoniae, Aeromonas sp., Mycobacterium tuberculosis, M. leprae, Candida sp., etc. (Waters and Basseler, 2005). This has made the scientists to explore new drugs either using plant sources like medicinal herbs or their parts or chemical sources. Due to the concern related to the side effects by the usages of chemical drugs (Hassan, 2012) made a shift in the path of drug usages and caused the public to use herbal medicinal sources for the treatment.

In the current research we have chosen Withania somnifera (Ashwagandha) fruit powder as the source with medicinal property for treating the common problem of vigour and vitality ailments in sexual problems. Among the plants known for medicinal value, the plants of genus Withania belonging to family Solanaceae are very important for their therapeutic potentials. $W$. coagulens, $W$. simonii, $W$. adunensis, and $W$. riebeckii are examples of known in the world and are also known to have medicinal properties (Atal and Kapoor, 1989; Sanyal, 1989; Chopra et al., 1993). W. somnifera is one of the major herbal components of geriatric tonics mentioned in Indian systems of medicine. In the traditional system of medicine Ayurveda, this plant is claimed to have potent aphrodisiac, rejuvenative and life prolonging properties. Recent research suggests a possible mechanism behind the increased cytotoxic effect of macrophages exposed to $W$. somnifera extracts (Davis and Kuttan, 2000). Before evaluating any medicinal plant, it is essential to understand its antioxidant potential because there are various free radicals released by our body and by various products intake (Abrahim et al., 1993; Gupta and Ray, 2004; Arawwala et al., 2010; Kumar et al., 2010). It has also been found that these free radicals remain as an adjuvant in causing cancer like skin cancer. This plant are used commonly as spices or as supplement in dietary items like tea and it is essential to evaluate the antioxidant potential of these drugs as observed to have high activity to scavenge the free radicals (Prakash et al., 2002). We have aimed to understand the scavenging potential of this plant as they are commonly used in India as a source for providing energetic booster and to treat sexual vigour and vitality problems in various parts of India. 


\section{MATERIALS AND METHODS}

\subsection{Collection of herbal plants}

Withania somnifera fruit powder was collected from Aravind Herbal Pvt. Ltd., Rajapalyam, Tamilnadu, India and was subjected for processing in PG and Research Department of Biotechnology, Kongunadu Arts and Science College, Coimbatore.

\subsection{Processing of $W$. somnifera fruit powder using cold percolation method}

The W. somnifera fruit powder was processed using cold percolation method as described by Adonizio et al. (2008). To retain the medicinal property of any medicinal plant, the cold percolation method is used and in this method, the powder was weighed and mixed with different solvents in 1:10 dilution, i.e., $3 \mathrm{~g}$ of powder with $30 \mathrm{ml}$ of solvents in increasing order of polarity such as petroleum ether, chloroform ethanol, hexane, methanol and distilled water. They were shaken well at $120 \mathrm{rpm}$ during the process to avoid fungal contamination and filtered using muslin cloth. The filtrate was kept in watch glass in dark for evaporation and scrapped powders were stored in dark bottle as they are light sensitive. The extracts were subjected to antioxidant scavenging activity and subjected for future research against pathogens.

\subsection{Evaluating the various antioxidant properties of extracted $W$. somnifera}

\subsection{1. $\mathrm{DPPH}{ }^{\bullet}$ scavenging activity}

The 2,2-diphenyl-1picryl hydrazyl (DPPH) scavenging activity of $W$. somnifera is performed using the method described by Blois, in 1995. DPPH is scavenged by antioxidants through the donation of a proton forming the reduced $\mathrm{DPPH}{ }^{\circ}$. In different test tubes, various concentrations of samples were taken along with Vitamin $\mathrm{C}$ as standard. The volume was adjusted to $500 \mu \mathrm{L}$ by adding methanol and $5 \mathrm{~mL}$ of $0.1 \mathrm{mM}$ methanolic solution of DPPH was added to these test tubes and vortexed. The tubes were allowed to stand at room temperature for $20 \mathrm{~min}$. The control was prepared as above without any extract and methanol was used for the baseline correction. The color change from purple to yellow after reduction can be quantified by its decrease in absorbance at wavelength $517 \mathrm{~nm}$. The percentage of inhibition radical scavenging activity was measured by the formula.

Percentage of radical scavenging activity $=\frac{\text { Control }- \text { Sample }}{\text { Control value }} \times 100$

The percentage inhibition vs. concentration was plotted and the concentration required for $50 \%$ inhibition of radicals was expressed as $\mathrm{IC}_{50}$ value.

\subsubsection{ABTS $^{\bullet+}$ radical scavengingactivity}

The test was based on the relative activity of antioxidants to quench the radical cation ABTS •+ (2,2'-azino-bis(3-ethylbenzothiazoline-6-sulphonic acid) ${ }^{+}$was done using the method described by Re $e t$ al. (1999). ABTS ${ }^{+}$decolorisation assay involves the generation of the $\mathrm{ABTS}^{+}$chromophore by the oxidation of ABTS with ammonium per sulphate. It is applicable for both hydrophilic and lipophilic compounds. The reaction was initiated by the addition of $1.0 \mathrm{~mL}$ of diluted ABTS to $10 \mu \mathrm{L}$ of different concentration of extract with high antibiofilm activity of the sample or $10 \mu \mathrm{L}$ of methanol serve as control. The absorbance was read at $734 \mathrm{~nm}$. Percentage inhibition was calculated by the formula

$$
\text { Percentage of radical scavengingactivity }=\frac{\text { Control }- \text { Sample }}{\text { Control value }} \times 100
$$

\subsubsection{Hydrogen Peroxide scavenging activity}

The hydrogen peroxide scavenging activity was measured in terms of a decrease in the absorbance as $230 \mathrm{~nm}$ in spectrophotometer using the method described by Ruch et al. (1989). A solution of $\mathrm{H}_{2} \mathrm{O}_{2}$ was prepared in phosphate buffer and the $\mathrm{H}_{2} \mathrm{O}_{2}$ concentration was determined using spectrophotometer at $230 \mathrm{~nm}$ wavelength. Various concentrations of plant extracts were added to $\mathrm{H}_{2} \mathrm{O}_{2}$ and incubated for 10 minutes. The absorbance at $230 \mathrm{~nm}$ was determined against a blank containing phosphate buffer without $\mathrm{H}_{2} \mathrm{O}_{2}$. The percentage of scavenging of $\mathrm{H}_{2} \mathrm{O}_{2}$ and standard compound Vitamin $\mathrm{C}$ was calculated using the formula:

Percentage of radicalscavengingactivity $=\frac{\text { Control -Sample }}{\text { Control value }} \times 100$

\subsubsection{Hydroxyl radical scavenging activity}

Hydroxyl radicals were generated from ferrous ammonium sulphate and EDTA were determined against the scavenging activity of the plant extracts using the method described by Klein et al. (1991). Different concentrations of plant extract were added with $1 \mathrm{~mL}$ of iron-EDTA solution ( $0.13 \%$ ferrous ammonium sulphate and $0.26 \%$ EDTA), 0.5 $\mathrm{ml}$ of EDTA solution (0.018\%), and $1 \mathrm{~mL}$ of DMSO $(0.85 \% \mathrm{v} / \mathrm{v}$ in $0.1 \mathrm{M}$ phosphate buffer, $\mathrm{pH} 7.4)$. The reaction was initiated by adding $0.5 \mathrm{ml}$ of ascorbic acid $(0.22 \%)$ and incubated at 80 to $90{ }^{\circ} \mathrm{C}$ for $15 \mathrm{~min}$ in a water bath. After incubation the reaction was 
terminated by the addition of $1 \mathrm{ml}$ of ice-cold trichloro acetic acid (TCA) $(17.5 \% \mathrm{w} / \mathrm{v})$. About $3 \mathrm{~mL}$ of Nash reagent $(75 \mathrm{~g}$ of ammonium sulphate, $3 \mathrm{~mL}$ of glacial acetic acid and $2 \mathrm{~mL}$ of acetyl acetone were mixed and make up to $1 \mathrm{~L}$ with distilled water) was added and left at room temperature for $15 \mathrm{~min}$. The reaction mixture without sample was used as control. This was detected by their ability to react with ascorbic acid to produce yellow color complex which was measured at $412 \mathrm{~nm}$ against reagent with blank. The percentage of hydroxyl radical scavenging activity is calculated by the following formula.

$$
\text { Percentage of radical scavenging activity }=\frac{\text { Control }- \text { Sample }}{\text { Control value }} \times 100
$$

\subsubsection{Ferric reducing antioxidant power (FRAP) assay}

The total antioxidant potential of sample was determined using ferric reducing antioxidant power (FRAP) using the method described by Benzie and Strain, 1996. The stock solution of $10 \mathrm{mM} \mathrm{2,} \mathrm{4,} \mathrm{6-}$ tripyridyl-s-triazine (TPTZ) in $40 \mathrm{mM} \mathrm{HCl}, 20 \mathrm{~mm}$ $\mathrm{FeCl}_{3}, 6 \mathrm{H}_{2} \mathrm{O}$ and $0.3 \mathrm{M}$ acetate buffer $(\mathrm{pH} 3.6)$ were prepared. The FRAP reagent contained $2.5 \mathrm{~mL}$ TPTZ solution, $2.5 \mathrm{~mL}$ ferric chloride solution and $25 \mathrm{~mL}$ acetate buffer. It was freshly prepared and warmed to $37{ }^{\circ} \mathrm{C} .900 \mu \mathrm{L}$ FRAP reagent were mixed with 90 $\mu \mathrm{L}$ water and $30 \mu \mathrm{L}$ test sample/ethanol/distilled water/standard antioxidant solution. The reaction mixture was then incubated at $37^{\circ} \mathrm{C}$ for $30 \mathrm{~min}$ and the absorbance was recorded at $595 \mathrm{~nm}$. An intense blue color complex were formed when ferric tripyridyl triazine ( $\mathrm{Fe}^{3+}$-TPTZ) complex were reduced to ferrous $\left(\mathrm{Fe}^{2+}\right)$ form. The absorption at $540 \mathrm{~nm}$ was recorded. The calibration curve was plotted with absorbance at $595 \mathrm{~nm}$ vs concentration of $\mathrm{FeSO}_{4}$ in the range $0.1 \mathrm{mM}$ ethanol solutions. The concentrations of $\mathrm{FeSO}_{4}$ were in turn plotted against concentration of standard antioxidants.

$$
\text { Percentage of radical scavenging activity }=\frac{\text { Control }- \text { Sample }}{\text { Control value }} \times 100
$$

\section{RESULTS AND DISCUSSION}

The processing and extraction of the $W$. somnifera powder was done accordingly and the methanolic and chloroform extract of $W$. somnifera were subjected for further scavenging activity analysis based on the work done by Prakash et al. (2002).

The methanol and chloroform extracts of $W$. somnifera were carried out with antioxidant test and identified that the free radical of the extract were found to have high percentage of inhibition against
DPPH•, ABTS $\bullet$, hydrogen peroxide, hydroxyl and FRAP. Vitamin $C$ served as the standard for all the antioxidant assays carried out in the study and when compared the methanolic extracts was higher than chloroform extract of $W$. somnifera. The results were observed to have higher percentage of inhibition for the extracts and the $\mathrm{IC}_{50}$ value was observed as $50 \mu \mathrm{g}$ /mL in all the tests (as shown in Fig. 1, 2, 3, 4 and 5) which was found to be similar to the results of Prakash et al., (2002).

Based on the experimental outcome of various researchers, additionally, levels of reduced glutathione, superoxide dismutase, catalase, and glutathione peroxidase in the exposed tissue returned to near normal values following administration of the extract. The chemo-preventive activity is thought to be due in part to the antioxidant/ free radical scavenging activity of the extract (Prakash et al., 2002). Antioxidant activities were measured using FRAP, DPPH, superoxide anion, nitric oxide and hyroxyl radical scavenging assays was also found to higher as the result obtained in the current research (Abrahim et al., 1993).

An in vitro study showed withanolides from $W$. somnifera inhibited growth in human breast, central nervous system, lung, and colon cancer cell lines comparable to doxorubicin. Withaferin A more effectively inhibited growth of breast and colon cancer cell lines than did doxorubicin. These results suggest $W$. somnifera extracts may prevent or inhibit tumor growth in cancer patients, and suggest a potential for development of new chemotherapeutic agents as well as found to inhibit various pathogens leading to act as antimicrobial agents.

\section{CONCLUSION}

This proves that both the methanolic and chloroform extracts of $W$. somnifera has higher scavenging activity and shows that these plant extracts can be further studied in future to understand the antibacterial activity as well as can serve as a potent drug in future pharmaceutical research for treating various common diseases and in cancer research.

\section{ACKNOWLEDGEMENT}

We acknowledge DBT-STAR College Scheme, Department of Biotechnology, New Delhi for their financial support and encouraging research in undergraduate level. We thank our management, Kongunadu Arts and Science College, for its infrastructure and laboratory support for this research work. 


\section{REFERENCES}

Abraham R., K. Angel and K. Ron, (1993). Protection of the rat jejunal mucosa against oxidative injury by cationized superoxide dismutase. J. Pharm. Sci. 82(12):1285-1287.

Adonizio A., K. Kok-Fai and M. Kalai, (2008). Inhibition of quorum sensing-controlled virulence factor production in Pseudomonas aeruginosa by South Florida plant extracts. Antimicrob Agents Chemother. 52(1):198-203.

Arawwawala, M., I. Thabrew, L. Arambewela and S. Handunnetti (2010). Anti-inflammatory activity of Trichosanthese cucumerina Linn. in rats. J. Ethanopharmacol. 131:538-43.

Atal, C. K. and B. M. Kapoor, (1989). Cultivation and utilization of medicinal plants (Eds. PID CSIR).

Benzie, I. F. F. and J. J. Strain, (1996). Ferric reducing ability of plasma (FRAP) as a measure of antioxidant power: The FRAP assay. Anal. Biochem. 239: 70-76.

Chopra, R. N., I. C. Chopra, K. L. Handa, et al., (1993). Indigenous drugs of India (Published by UN Dhar, Pvt. Ltd., Calcutta).

Davis, L., and G. Kuttan, (2000). Immunomodulatory activity of W.somnifera. J. Ethnopharmacol. 71:193-200.

Gupta, P. C., and C. S. Ray (2004). Epidemiology of betel quid usage. Ann. Acad. Med. 33(4):31-36.

Hassan Bassam Abdul Rasool, (2012). Main critical side effects associated with chemotherapy used in cancer treatment. Pharm. Analytica Acta. 3(5):1000e113.

Klein S. M., G. Cohen and A. I. Cederbaum, (1991). Production of formaldehyde during metabolism of dimethyl sulphoxide by hydroxyl radical radical generating system. Biochemistry. 20: 6006-6012.

Kumar A., Garg B. R., Rajput G., Chandel D., Muwalia A., Bala I. and Singh Sumeer, (2010). Antibacterial activity and quantitative determination of protein from leaf of Datura stramonium and Piper betle plants. Pharmacophore. 1(3):184-195.

Prakash, J., S. K. Gupta, and A. K. Dinda, (2002). W.somnifera root extract prevents DMBAinduced squamous cell carcinoma of skin in Swiss albino mice. Nutrition and Cancer. 42:9197.
Re R., N. Pelligrini, A. Proteggeenate, M. Yang and C. Rice-Evans (1999). Antioxidants activity of applying an improved ABTS radical cation decolorisation assay. Free Radic. Biol. Med. 26: 1231-1237.

Ruch R., S. Cheng and J. Klauning, (1989). Prevention of cytoxicity and inhibition of intercellular communication antioxidant catechins isolated from Chinese green tea. Carcinogenesis. 10: 1003-1008.

Samhita Charaka, (1997). Chikitsa Sthana, Second Chapter, Chowkambha Publishers, 38 (English Edition).

Sanyal, P. K. (1989). Homeopathic Pharmacy in India. In: Cultivation and utilization of medicinal plants. Editor: Atal C. K. and Kapoor B. M. (Published by PID CSIR).

Waters, C. M. and B. L. Bassler, (2005). Quorum sensing: cell-to-cell communication in bacteria. Annu. Rev.Cell Dev. Biol. 21: 319-346.

WHO survey, (2009). In medicinal plants (Eds. Haq. I.) Hamdard Foundation Press, Karachi, 13.

Fig. 1. DPPH• radical scavenging activity of $W$. somnifera

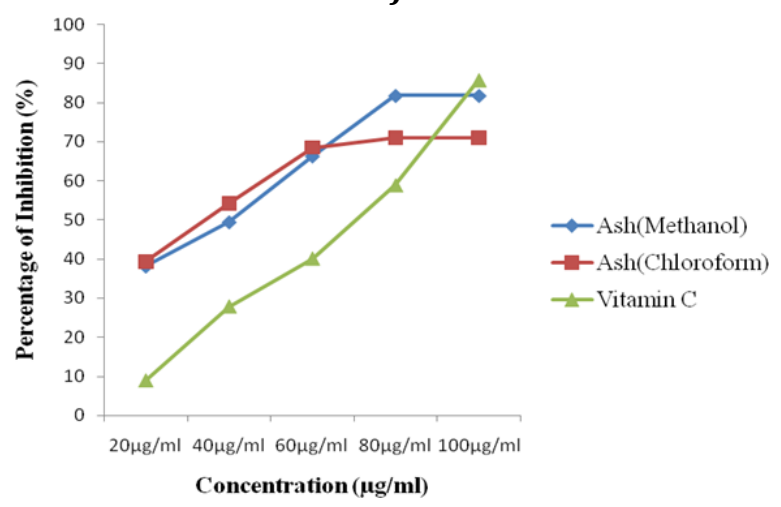

Fig. 2. ABTS ${ }^{\bullet+}$ radical scavenging activity of $W$. somnifera

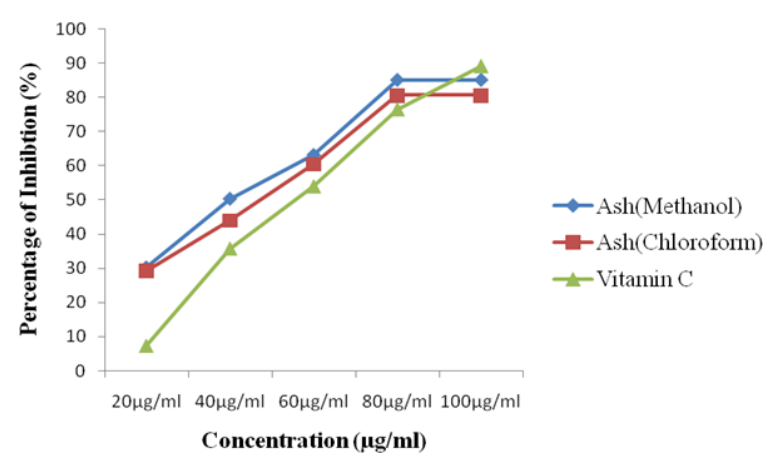


Fig. 3. Hydroxyl radical scavenging activity of $W$. somnifera

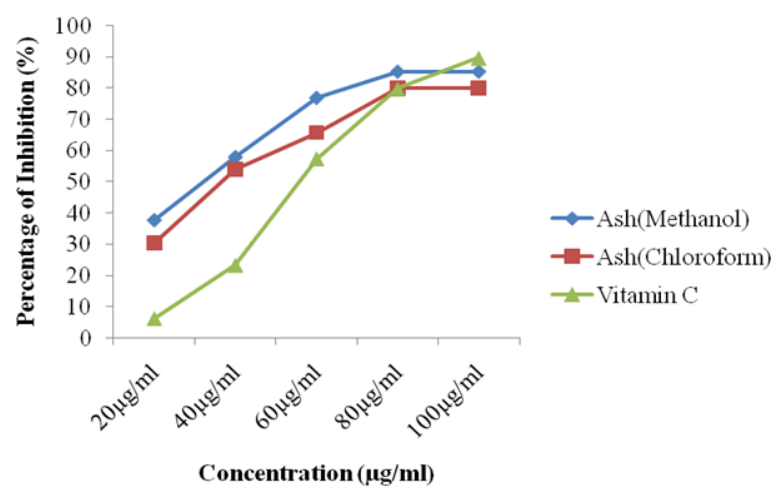

Fig. 4. Hydrogen peroxide radical scavenging activity of $W$. somnifera

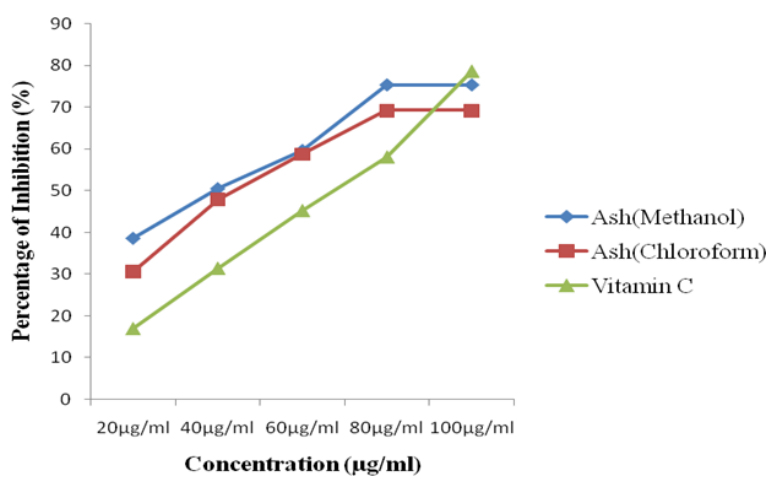

Fig. 5. FRAP radical scavenging activity of $W$. somnifera

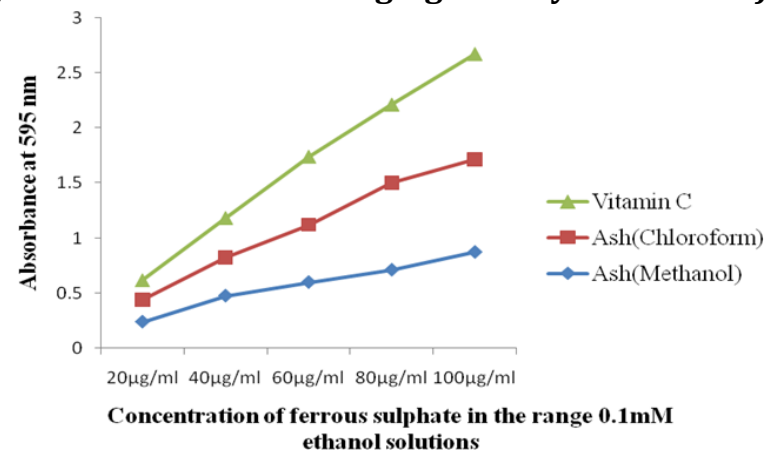

